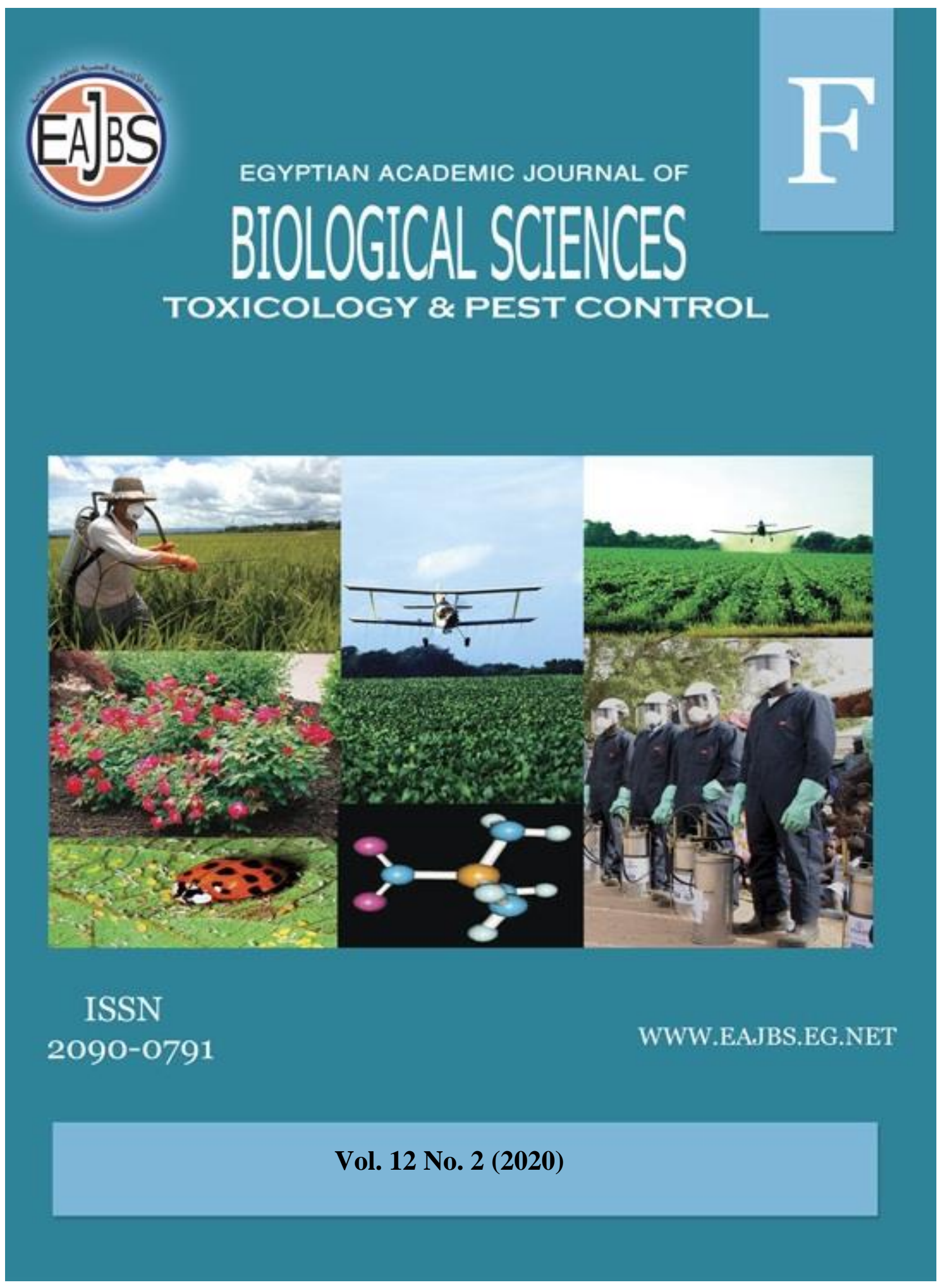


Egypt. Acad. J. Biolog. Sci., 12(2): 97-108 (2020)

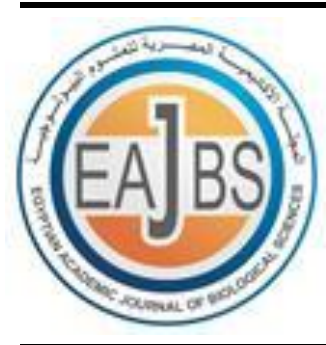

Egyptian Academic Journal of Biological Sciences

F. Toxicology \& Pest Control

ISSN: 2090 - 0791

http://eajbsf.journals.ekb.eg/

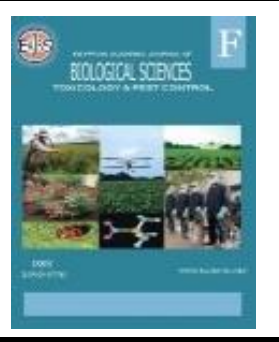

\title{
Pregnancy Outcome in Female Rats Exposed to Bispyribac Sodium and Ameliorative Effect of Nigella Sativa Oil
}

\author{
Sanaa, M. Abdulrhman, Nahas, A.A. and Reem, M. Ziada \\ Mammalian and Aquatic Toxicology Department, Central Agricultural Pesticides Lab. \\ (CAPL), Agricultural Research Center, Ministry of Agriculture, Dokki, Giza 12618, \\ Egypt \\ E.mail : abdelhamidnahas7@gmail.com-zorosonds@yahoo.com
}

\begin{abstract}
ARTICLE INFO
Article History

Received:22/6/2020

Accepted:21/9/2020

Key words:

Fetotoxicity maternal toxicity-

Bispyribac

Sodium- nigella

sativa oil-

oxidative stress

\section{ABSTRACT}

Bispyribac sodium is commonly used as a herbicide worldwide. Few studies had investigated the health impact of exposure to it. Redox homeostasis has a great role during organogenesis through in cell growth, differentiation, and death. The aim of this study is to investigate the redox homeostasis imbalance and teratogenic effect of BPS in female rats exposed to bispyribac sodium (BPS) during organogenesis and evaluates the protective role of Nigella Sativa Oil (NSO). Pregnant female rats were grouped into four groups, negative and positive (NSO) control groups. While the others, BPS with and without NSO treatment groups. Results showed that BPS exposure during the pregnancy led to maternal and fetotoxicity as evidenced by preimplantation, post-implantation loss, reduction in placenta weight, reduction in fetal weight, fetal length, skeletal anomalies (incomplete ossification, misaligned sternbrae), visceral malformation (anophthalmia, microphthalmia, internal hydrocephaly, and microcephaly) and oxidative stress in dams serum. NSO treatment exhibited amelioration in the aforementioned maternal and fetotoxicity against BPS exposure.
\end{abstract}

\section{INTRODUCTION}

Owing to industrial development, the entire populations have been exposed to many chemical substances such as pesticides, and metals. One downside is that in some or all of its phases, many of these chemicals can disrupt reproductive capacity, such as early embryogenesis, egg fertilisation, and embryo implantation (Caserta, Graziano et al., 2013, Gundacker, Neesen, et al., 2016). Pesticides are regarded as powerful pollution of the environment that has been concerned with birth defects and reproductive failure. The detrimental fitness results correlated with publicity to pesticides throughout pregnancy have grown to be widespread public health due to the huge use of pesticides and the rising instability of the fetus and the pregnant mother to poisonous exposures (Stillerman, Mattison, et al., 2008)

Pesticides are well established to traverse the placental barrier and may cause certain modifications in the formation of placental architectures. Placental injury caused by drugs or contaminants then results in retardation of fetal development, resorption, or

Citation: Egypt. Acad. J. Biolog. Sci. (F. Toxicology \& Pest control) Vol. 12(2) pp.97- 108 (2020) 
teratogenicity (El Ghareeb et al., 2015).

Studies suggest an association between environmental exposure of pregnant women to certain agricultural pesticides and malformation in their fetuses (Peiris-John and Wickremasinghe 2008). The most susceptible period for fetal anomalies to take place is the period of organogenesis (from 6-15 days of gestation). Drugs and chemicals given during this period are more likely to cause fetal defects (Gabr et al., 2015).

Indeed, epidemiological studies have observed causality to adverse effects on pregnancy outcomes, such as decreased fetal body weight and premature birth, when higher concentrations of chemicals are present in the environment (Apostoli and Catalani, 2015)

Bispyribac-sodium is a pyrimidinylcarboxy herbicide, used to control grasses, sedges, and broadleaved weeds. The solubility of this compound in the water of $73.3 \mathrm{~g} / \mathrm{L}$ and has a half-life of 60-days. Noncompetitively inhibition of acetoacetate synthase enzyme (ALS) is the main mechanism of this herbicide. This mechanism disrupts the synthesis of the amino acids valine, leucine, and isoleucine resulting in disruption of cell division and plant growth. Biochemical changes in fish were induced by BPS (Toni, de Menezes, et al., 2010).

Oxidative stress has been suggested as a contributing factor in fetal developmentrelated disorders such as embryonic resorption, repeated pregnancy failure and intrauterine growth restriction (IUGR) and fetal impairment (Gupta, Sarotra, et al. 2007). Regulated generation of ROS is an essential constituent mechanism and is one of the key elements in cell signalling, gene expression (Al-Gubory, Fowler et al., 2010). redox homeostasis, invasive signal transduction pathways and signal transduction pathways involved in cell function, growth, differentiation, and death (Valko, Leibfritz et al., 2007).

Nigella sativa L. (Black seed) possesses therapeutic properties such as antioxidative (Alenzi et al., 2013), immunomodulatory, anti-inflammatory (Majdalawieh and Fayyad 2015), neuroprotective (Islam et al., 2015), genoprotective (Al-shdefat et al.,2014) Previously published studies have shown that Nigella sativa ( $N$. sativa) oil (NSO) has been reported to have anti-inflammatory, antioxidant and immunomodulatory, anti-carcinogenic, anti-hypertensive, and anti-ischemic properties (Majdalawieh and Fayyad 2015).Nigella. Sativa is recognized because of its role in improving the reproductive performance of male rats (Al-Sa'aidi et al., 2009). In addition to that, the crude N. Sativa fixed oil. and thymoquinone (TQ) also have been found to suppress lipid peroxidation in the membrane (Kanter 2011) and improve antioxidant protection mechanisms (Mohamadin et al., 2010).

We need a deeper understanding of the antioxidant developmental events that occur between embryonic implantation and parturition when pregnant dams exposed to Bispyribac-sodium. These studies are expected to provide insights into ROS-mediated evolutionary antioxidant responses during regular and disrupted pregnancy and to promote the prevention of pregnancy-related disorders by natural product antioxidants.

\section{MATERIALS AND METHODS}

\section{Herbicides and Chemicals:}

Bispyribac sodium (Bero 2\% EC) was gained from Mammalian Toxicology Dept., Central Agricultural Pesticides Lab. (CAPL), Agriculture Research Center (ARC), Dokki, Giza, Egypt. All chemicals used in this paper were obtained from Sigma Company. Nigella sativa Oil (NSO) was obtained from a local shop of medicinal plants, Giza Egypt packed in a dark brown bottle. 


\section{Experimental Animals:}

Throughout this study, male and nulliparous female albino rats of 10 weeks old were used. Animals were reared on an ad libitum basal diet and tap water. The animals were kept in an environmental condition kept at $23 \pm 3{ }^{\circ} \mathrm{C}$ temperatures and $50 \pm 5$ percent relative humidity with lighting12-hour. The study was conducted in accordance with the national guidelines for the care and use of laboratory animals. Two females were put into each male's cage for overnight mating. The presence of sperm in a vaginal smear determined successful mating, and the following first 24-h was known as zero-day of gestation.

\section{Grouping of Animals:}

Positively matted females were split randomly into three groups plus one control group (each included eight pregnant female rats). Group I: was given orally with $1 \mathrm{ml} / \mathrm{kg} /$ day of distilled water as the guide. Group II: BPS animals were administered a $4.38 \mathrm{mg} / \mathrm{kg} /$ day $\left(\mathrm{LD}_{50} / 40\right.$ ) dose of BPS, the LD50.of the herbicide was determined according to the OECD NO 423. Group III: (NSO), rats were provided with $1 \mathrm{ml} / \mathrm{kg} / \mathrm{day}$ of $N$. sativa oil based on the (Mansour, Sangi, et al. 2013, Mosbah, Yousef, et al. 2016) studies. Group IV: (NSO+BPS): $1 \mathrm{ml} / \mathrm{kg} /$ day of NSO oil was given to animals, then provided with $4.38 \mathrm{mg} / \mathrm{kg} / \mathrm{day}$ of BPS after two hours. Administration BPS and NSO were carried out from 6-15 days of pregnancy period.

\section{Blood and Liver Organ Sampling:}

At the end of the experiment, blood samples were collected from pregnant dams by decapitation in the $20^{\text {th }}$ of pregnancy before delivery in clean tubes for obtaining the serum. Serum collected from blood samples after centrifugation at $3600 \mathrm{rpm}$ for $10-\mathrm{min}$ at $4{ }^{\circ} \mathrm{C}$ was stored at $-20^{\circ} \mathrm{C}$ until biochemical analysis of oxidative stress biomarkers (MDA, GSH, GST, and CAT). The liver was excised from the animals and preserved in formalin saline buffer for histopathological analysis.

\section{Manipulation of Pregnant Rats and Evaluation of Fetuses:}

The separated uterine horns were completely removed to display the fetuses and placentas, which were then gently removed. The weight of removing fetuses and the length of the fetal crown-rump were measured.

\section{Skeletal Evaluation of the Fetuses:}

Internal fetal organs were eliminated by a tiny hole through the anterior abdomen. They rinsed with 95\% ethyl alcohol and then dehydrated for 7-10 days in 95\% ethyl alcohol. The specimens were then washed in a $\mathrm{KOH}(1 \%)$ solution until the bones were clearly visible through the surrounding tissue and moved to a $\mathrm{KOH}$ fresh solution containing alizarin red stain. Eventually, the specimens were moved to solutions containing respectively 30,50, and 70\% glycerin and deposited in pure glycerin.

\section{Visceral Examination of Fetuses:}

Half of the fetuses from each dam were kept in Bouin solution for 1-2 weeks. Then, the fetuses were rinsed with cold water and several cross-sections were made throughout the fetal body. Fetal sections were grossly examined under a dissecting microscope for any visceral malformations (Hayes, 1986).

\section{Biochemical Markers of Redox Homeostasis in Dam Serum:}

\section{Determination of Glutathione-S-Transferase (GST) Activity:}

The activity of glutathione-S-transferases (GST) was determined at $340 \mathrm{~nm}$ in the reaction medium contained phosphate buffer (0.1M, pH 6.5), GSH (1.0 mM), 1-chloro 2, 4-dinitrobenzoic acid (1.0mM) and a sample (Habig et. al., 1974). GST activity was expressed as $\mathrm{U} / \mathrm{ml}$. 


\section{Determination of Catalase (CAT) Activity:}

Catalase activity (CAT) was measured by the method of (Aebi 1984) The reaction started by adding $\mathrm{H}_{2} \mathrm{O}_{2}(30 \mathrm{mM})$ to an appropriate volume of homogenate in $50 \mathrm{mM}$ sodium phosphate buffer with $\mathrm{pH}$ 7. Then, the absorbance was read at a wavelength of $240 \mathrm{~nm}$ within 3-min. The CAT activity was expressed as U/ml.

\section{Determination of Reduced Glutathione (GSH) level:}

Reduced glutathione content (GSH) estimation of supernatant was performed by the method of (Beutler, Duron, et al. 1963). The determination of GSH is based on the reaction of DTNB [5, 50-dithiobis-(2-nitrobenzoic acid)] with GSH yielding a yellowcoloured chromophore with a maximum absorbance at $412 \mathrm{~nm}$. The amount of GSH present in the selected tissue was calculated as $\mathrm{nmol} / \mathrm{ml}$.

\section{Biomarker of Oxidative Stress (lipid peroxidation)}

Malondialdhyde (MDA) content as a lipid peroxidation end product of the homogenates was determined according to the method of (Ohkawa, Ohishi, et al. 1979). The reaction mixture, containing $8.1 \%$ sodium (SDS) dodecyl sulfate, $20 \%$ acetic acid (pH 3.3), and $0.8 \%$ thiobarbituric acid, was placed in a boiling water bath for $60-\mathrm{min}$. After cooling, an $n$-butanol and pyridine mixture (15:1 v/v) was added and then shaken vigorously and centrifuged at $3000 \mathrm{rpm}$ for 10 -min at $4{ }^{\circ} \mathrm{C}$. The absorbance of the supernatant was measured spectrophotometrically at $532 \mathrm{~nm}$ at room temperature. MDA level was expressed as $\mathrm{nmol} / \mathrm{ml}$.

Histopathological Assessment:

The liver was excised from the animals and preserved in $10 \%$ buffered formalin overnight for histopathological analysis. Samples embedded with paraffin was sectioned at $4 \mu \mathrm{m}$, deparaffinized in xylene, dehydrated by ethyl alcohol in a decreasing concentration $(100 \%, 95 \%$ \& $70 \%)$, and stained with haematoxylin and eosin stain (Banchroft et al., 1996). the specimens were examined by a light microscope at $40 \times$ magnification powers and imaged with digital images.

\section{RESULTS}

Maternal and fetal values were recorded in Table (1). The data indicated that maternal toxicity as the number of corpora lutea, corpora lutea /litter, the number of implants, placenta weight, and placenta index/dam were significantly declined in rats administered the BPS at a dose of $\left(4.38 \mathrm{mg} / \mathrm{kg} / \mathrm{day}\left(\mathrm{LD}_{50} / 40\right)\right.$. Also, the results indicated that preimplantation and post-implantation loss was significantly increased in female rats exposed to BPS herbicides.

From the same table, the data show that the administration of NSO concomitant with BPS exposure improved all maternal toxicity in comparison with the BPS group. The tested dose of BPS herbicides induced fetal toxicity as evidenced by a significantly reduction in the average fetal weight, fetal length, (Fig 1A) a live fetus, and placenta index/feus comparing with the control groups. NSO concomitant with BPS exposure improved all fetal toxicity biomarkers in comparison with the BPS group.

Incidence of skeletal anomalies in fetuses obtained from dams exposed to BPS as depicted in Table (2) and figure (1 B) indicated a higher incidence of skeletal anomalies in fetuses. Skeletal malformations recorded in this study were incomplete ossification of the skull bones, missing \& incomplete ossification of the hyoid bone, and incomplete ossification \& misaligned sternbrae. As well as, the BPS-exposed group, pregavaged by NSO could modulate these anomalies.

Several visceral anomalies in fetuses obtained from dams received BPS while those pre-treated with NSO showed amelioration in certain malformations. Such 
malformations as anophthalmia, microphthalmia, (Fig1C) internal hydrocephaly, and microcephaly (Fig 1D) were occurred recorded in Table (3).

The data presented in Table (4) show the effect of BPS on oxidative stress markers in the serum of pregnant female rats. The data indicate that BPS exposure during the organogenesis period induced oxidative stress biomarkers in dam's serum as evidenced by the significant decrease in CAT, GST activity, and GSH content regarding a significant increase in MDA level as lipid peroxidation biomarkers as compared with the control group. NSO administration showed amelioration in these biomarkers in comparison with BPS without returning to control group levels.

Table 1: Maternal and fetal values of rats exposed to Bispyribac with or without Nigella Sativa Oil.

\begin{tabular}{|c|c|c|c|c|}
\hline $\begin{array}{c}\text { Maternal and Feto } \\
\text { Indices } \\
\end{array}$ & $\begin{array}{c}\text { Control } \\
(1 \mathrm{ml} / \mathrm{Kg})\end{array}$ & $\begin{array}{c}\mathrm{NSO} \\
(1 \mathrm{ml} / \mathrm{kg} / \text { day }) \\
\end{array}$ & $\begin{array}{c}\text { BPS } \\
(4.38 \mathrm{mg} / \mathrm{Kg}) \\
\end{array}$ & $\begin{array}{c}\text { BPS }(4.38 \mathrm{mg} / \mathrm{Kg}) \\
\& N S O(1 \mathrm{ml} / \mathrm{kg} / \mathrm{day}) \\
\end{array}$ \\
\hline $\begin{array}{c}\text { No of Corpora } \\
\text { Lutea }\end{array}$ & $8.625^{\mathrm{a}} \pm 0.53$ & $10.375^{b} \pm 0.32$ & $9.125^{\mathrm{a}} \pm 0.64$ & $10.5^{b} \pm 0.53$ \\
\hline $\begin{array}{c}\text { Corpora } \\
\text { Lutea/litter }\end{array}$ & $1.21^{\mathrm{a}} \pm 0.11$ & $1.24^{\mathrm{a}} \pm 0.09$ & $0.88^{b} \pm 0.3$ & $1.52^{\mathrm{a}} \pm 0.11$ \\
\hline No of Implantation & $7.38^{\mathrm{a}} \pm 0.59$ & $9.13^{\mathrm{a}} \pm 0.55$ & $7.75^{\mathrm{a}} \pm 0.65$ & $9.75^{b} \pm 0.7$ \\
\hline $\begin{array}{c}\text { Pre implantation } \\
\text { Loss }\end{array}$ & $8.15 \pm 3.02$ & $5.22 \pm 2.01$ & $13.04 \pm 2.0$ & $5.45 \pm 1.60$ \\
\hline $\begin{array}{l}\text { Post implantation } \\
\text { Loss }\end{array}$ & 0.00 & 0.00 & $42.46^{b} \pm 17.17$ & $25.23^{\mathrm{a}, \mathrm{b}} \pm 5.34$ \\
\hline Placenta Weight & $3.60^{\mathrm{a}} \pm 0.17$ & $3.58^{\mathrm{b}} \pm 0.28$ & $2.69^{b} \pm 0.22$ & $3.60^{\mathrm{a}} \pm 0.33$ \\
\hline $\begin{array}{c}\begin{array}{c}\text { Placneta Dam } \\
\text { Index }\end{array} \\
\end{array}$ & $7.22^{\mathrm{a}} \pm 0.2$ & $7.33^{\mathrm{a}} \pm 0.21$ & $6.21 \pm 0.38$ & $7.66^{\mathrm{a}} \pm 0.26$ \\
\hline Liver Dam Index & $11.38 \pm 0.31$ & $11.64 \pm 0.17$ & $11.06 \pm 0.36$ & $11.54 \pm 0.4$ \\
\hline Live Fetus & $7.38^{\mathrm{a}} \pm 0.59$ & $8.63^{a} \pm 0.65$ & $4.38^{\mathrm{b}} \pm 1.44$ & $7.13^{\mathrm{a}} \pm 0.64$ \\
\hline Fetus Weight & $3.54 \pm 0.06$ & $3.32^{\mathrm{a}} \pm 0.03$ & $2.55^{b} \pm 0.1$ & $3.2^{\mathrm{a}} \pm 0.12$ \\
\hline Fetus Length & $3.65^{a} \pm 0.11$ & $3.39^{\mathrm{a}} \pm 0.04$ & $2.91^{\mathrm{b}} \pm 0.24$ & $3.12^{b} \pm 0.03$ \\
\hline Placenta Index & $0.49^{\mathrm{a}} \pm 0.04$ & $0.49^{a} \pm 0.03$ & $0.37^{b} \pm 0.04$ & $0.44^{\mathrm{a}, \mathrm{b}} \pm 0.03$ \\
\hline Sex Ratio & $1.43^{\mathrm{a}} \pm 0.39$ & $0.69^{\mathrm{a}, \mathrm{b}} \pm 0.13$ & $0.28^{b} \pm 0.04$ & $0.76^{a} \pm 0.27$ \\
\hline Live Fetus & $7.38^{\mathrm{a}} \pm 0.59$ & $8.63^{a} \pm 0.65$ & $4.38^{\mathrm{b}} \pm 1.44$ & $7.13^{a} \pm 0.64$ \\
\hline
\end{tabular}

a significance comparing with control b significance comparing with control

c significance comparing with control d significance comparing with control

Table 2: Skeletal Anomalies in Rat fetus after Maternal Exposure to Bispyribac with or without Nigella Sativa Oil.

\begin{tabular}{|c|c|c|c|c|}
\hline $\begin{array}{c}\text { Maternal and Feto } \\
\text { Indices }\end{array}$ & $\begin{array}{c}\text { Control } \\
(\mathbf{1 m l} / \mathbf{K g})\end{array}$ & $\begin{array}{c}\text { NSO } \\
(\mathbf{m l} / \mathbf{k g} / \mathbf{d a y})\end{array}$ & $\begin{array}{c}\text { BPS } \\
(\mathbf{4 . 3 8} \mathbf{~ m g} / \mathbf{K g})\end{array}$ & $\begin{array}{c}\text { BPS (4.38mg/Kg) } \\
\text { \&NSO (1 ml/kg/day) }\end{array}$ \\
\hline No of detected fetus & $\mathbf{2 8}$ & $\mathbf{2 8}$ & $\mathbf{1 8}$ & $\mathbf{2 2}$ \\
\hline $\begin{array}{c}\text { Absence of } \\
\text { Sternbrae }\end{array}$ & $2(7.14)$ & - & $7(38.9)$ & 2 \\
\hline $\begin{array}{c}\text { Absence of } \\
\text { Hyoid Bone }\end{array}$ & - & - & $3(16.7)$ & $1(4.5)$ \\
\hline $\begin{array}{c}\text { Incomplete } \\
\text { Ossification of } \\
\text { Hyoid Bone }\end{array}$ & - & & $5(27.7)$ & \\
\hline $\begin{array}{c}\text { Incomplet } \\
\text { Ossified Skull }\end{array}$ & $2(7.14)$ & & $5(27.7)$ & $2(9)$ \\
\hline Bipertite Sternbrae & - & & $2(11.1)$ & - \\
\hline $\begin{array}{c}\text { Absence of } \\
\text { Tail Vertebral }\end{array}$ & - & & $4(2.22)$ & - \\
\hline Wavy Ribs & - & & $4(2.22)$ & \\
\hline
\end{tabular}

The in bracket express percentage $\%$. 
Table 3: Visceral anomalies in rat fetus after maternal exposure to Bispyribac with or without Nigella Sativa Oil.

\begin{tabular}{|c|c|c|c|c|}
\hline $\begin{array}{c}\text { Maternal and Feto } \\
\text { Indices }\end{array}$ & $\begin{array}{c}\text { Control } \\
(\mathbf{1 m l / K g})\end{array}$ & $\begin{array}{c}\text { NSO } \\
(\mathbf{m} \mathbf{m} / \mathbf{k g} / \mathbf{d a y})\end{array}$ & $\begin{array}{c}\text { BPS } \\
(\mathbf{4 . 3 8} \mathbf{~ m g} / \mathbf{K g})\end{array}$ & $\begin{array}{c}\text { BPS (4.38mg/Kg) } \\
\text { \&NSO (1ml/kg/day) }\end{array}$ \\
\hline No of Detected Fetus & $\mathbf{2 8}$ & $\mathbf{2 8}$ & $\mathbf{1 8}$ & $\mathbf{2 2}$ \\
\hline $\begin{array}{c}\text { Internal } \\
\text { Hydrocephaly }\end{array}$ & - & - & $6(33.2)$ & - \\
\hline Microcephaly & - & - & $3(16.6)$ & - \\
\hline $\begin{array}{c}\text { Hydrocephaly } \\
\text { \&Microcephaly }\end{array}$ & - & - & $4(22.22)$ & $2(9.09)$ \\
\hline Anaphthalmia & - & - & $2(11.1)$ & $1(4.5)$ \\
\hline Microphthalmia & - & - & $3(16.6)$ & $2(9.09)$ \\
\hline Pelvic Kideny & - & - & $4(22.2)$ & \\
\hline
\end{tabular}

The in bracket express percentage $\%$.

Table 4: Serum oxidative stress biomarker of pregnant female rats exposed to Bispyribac with or without Nigella Sativa Oil.

\begin{tabular}{|c|c|c|c|c|}
\hline $\begin{array}{c}\text { Oxidative } \\
\text { Stress } \\
\text { Biomarker } \\
\end{array}$ & $\begin{array}{c}\text { Control } \\
(1 \mathrm{ml} / \mathrm{Kg})\end{array}$ & $\begin{array}{c}\text { NSO } \\
(1 \mathrm{ml} / \mathrm{kg} / \text { day })\end{array}$ & $\begin{array}{c}\text { BPS } \\
(4.38 \mathrm{mg} / \mathrm{Kg})\end{array}$ & $\begin{array}{c}\text { BPS }(4.38 \mathrm{mg} / \mathrm{Kg}) \\
\text { \&NSO }(1 \mathrm{ml} / \mathrm{kg} / \mathrm{day})\end{array}$ \\
\hline CAT & $12.56^{\mathrm{a}} \pm 1.17$ & $10.468^{a, c} \pm 0.53$ & $4.19^{b} \pm 0.44$ & $8.72^{c} \pm 1.35$ \\
\hline GST & $109.38^{\mathrm{a}} \pm 4.03$ & $109.38^{\mathrm{a}} \pm 4.03$ & $72.91^{b} \pm 4.36$ & $81.04^{b} \pm 2.34$ \\
\hline GSH & $524.5^{\mathrm{a}} \pm 3.62$ & $506.25^{b} \pm 4.06$ & $339.25^{c} \pm 4.26$ & $422.9^{\mathrm{d}} \pm 4.23$ \\
\hline MDA & $46.26^{a} \pm 0.29$ & $47.4^{\mathrm{a}} \pm 0.74$ & $101.31^{\mathrm{b}} \pm 2.58$ & $54.84^{c} \pm 2.51$ \\
\hline
\end{tabular}

a significance comparing with control b significance comparing with control

c significance comparing with control d significance comparing with control

\section{Histopathology Examination:}

Microscopically, the liver of control and NSO groups revealed the normal histological structure of hepatic lobules with no histopathological alterations (Figs. 2I \& 2 II). Meanwhile, the BPS-exposed group, pathological examination of the liver showed cytoplasmic vacuolization of hepatocytes, focal hepatic necrosis associated with inflammatory cells infiltration, and portal fibrosis (Figs. 2III \& 2IV). On the other hand, the rat's group exposed to the herbicide concomitant with NSO revealed slight cytoplasmic vacuolization of some hepatocytes and portal infiltration with inflammatory cells (Fig.2V). Whereas, other sections revealed apparent normal hepatic tissue (Fig. 2VI). 


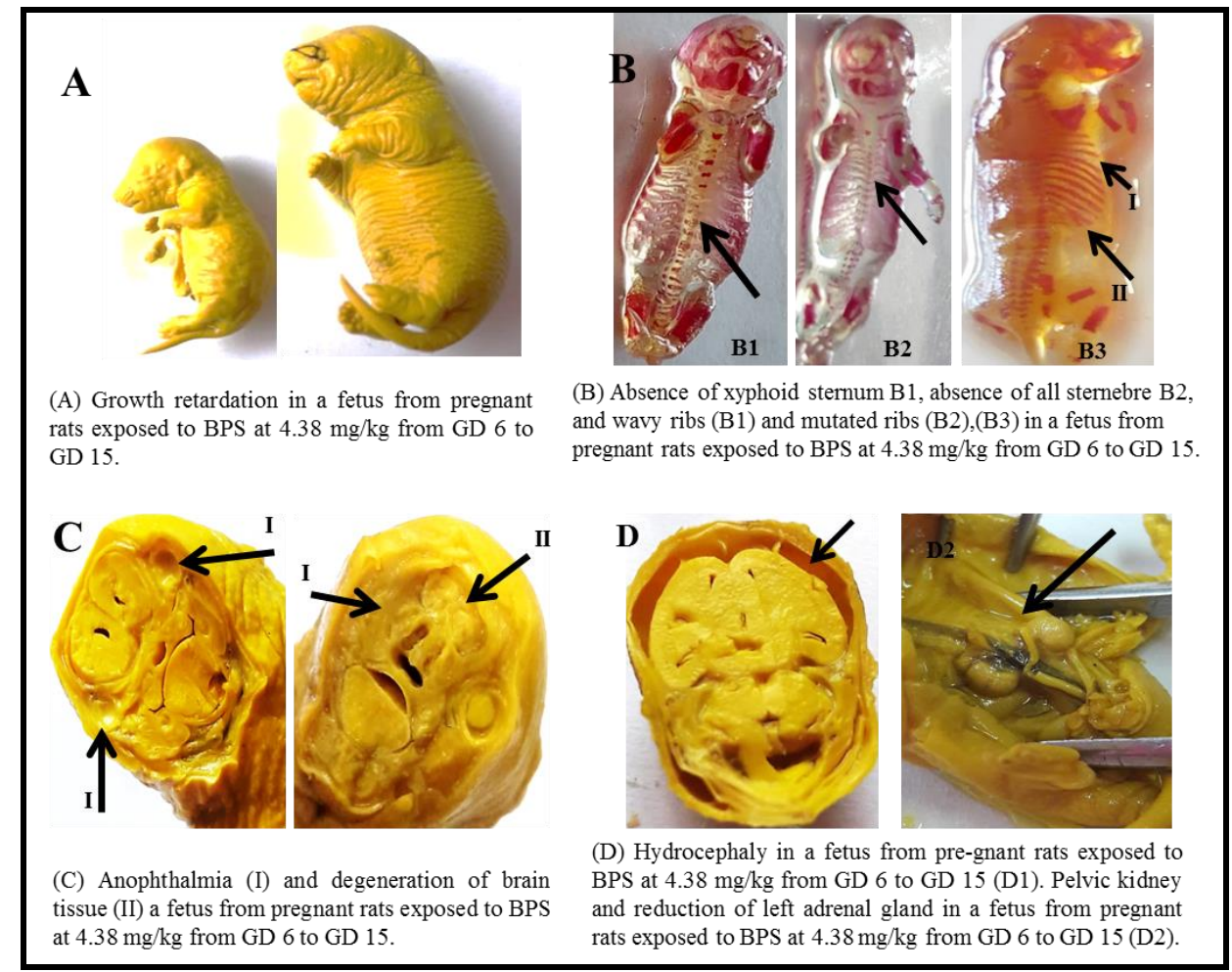

Fig. 1: Skeletal Anomalies\& Visceral anomalies in rat fetus after maternal exposure to Bispyribac with or without Nigella Sativa Oil.

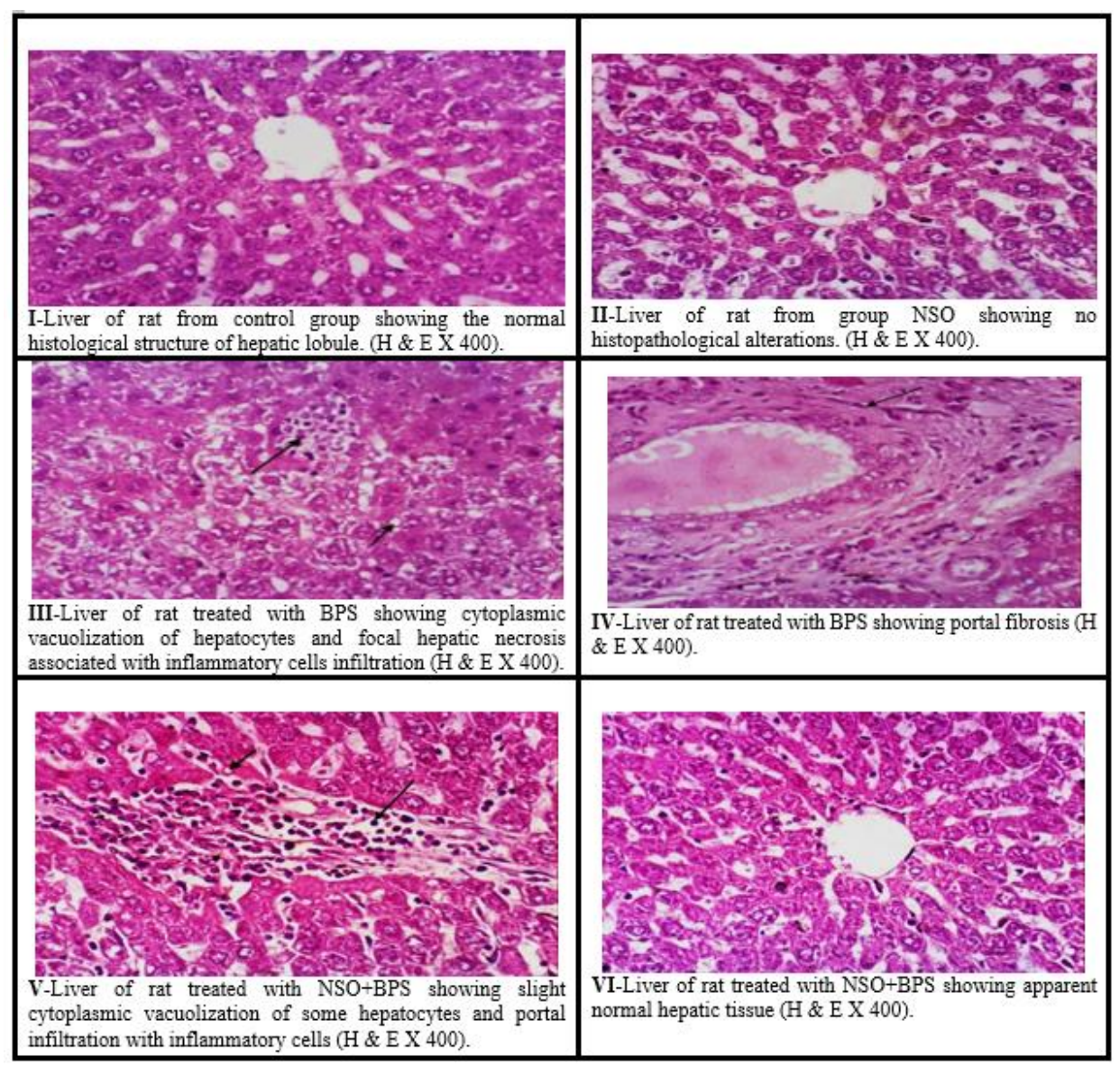

Fig.2: Pathological examination of dam liver exposed to Bispyribac with or without Nigella Sativa Oil during gestation period. 


\section{DISCUSSION}

Regarding maternal factors responsible for implantation, the effective implantation entails that the embryos progress to the blastocyst stage and an extensive uterine preparation system (Varayoud, Ramos, et al., 2014). Establishing a uterine environment to enable implantation of blastocysts mainly depends on the synchronized actions of estrogen, ovarian steroids that trigger the gene transcription, which promotes uterine epithelial cells and stroma proliferation and differentiation. Therefore, impaired uterine growth and differentiation may be a major contributing factor to infertility (Milesi et al., 2014). The post-implantation phase is a crucial time of gestation due to the increased sensitivity to ROS-induced oxidative damage to meet the necessary requirements of the developing conceptus for energy (Alcolea, Colom, et al., 2007) the transition from pre-implantation embryonic anaerobic metabolism to post-implantation aerobic metabolism may occur, exposing embryonic cells to ROS generated as byproducts of the increased respiratory capability of embryonic mitochondria (Alcolea, Colom, et al., 2007) During the time of organogenesis, these modifications occur when the embryo becomes exposed to environmental teratogens such as heavy metals and pesticides. Increased oxidative stress is associated with miscarriage during the establishment of cellular and biochemical interactions between the uterus and postimplantation (Al-Gubory, Fowler, et al., 2010).

The placenta is necessary for material passage between both the fetal and maternal circulations. Therefore, the growth of the fetus is closely related to the placenta's communication functions. The size of a fetus at delivery day directly represents the net flow of water and solutes in the placenta during the gestation period (Desforges and Sibley 2010). A smaller placenta is likely to have lower blood flow, resulting in severe fetal hypoxia that may cause intrauterine growth to slow. The marked decrease of placental weight in rats can affect its nutritional function, resulting in resorption or at least growth dysfunction (Gabr et al., 2015). One of the pathways connecting altered placental function with fetal programming could be oxidative stress (Myatt 2006).

Fetuses and newborns are more susceptible to the harmful effects of some contaminants since they have reduced rates of detoxification enzymes deactivating these chemicals (Oyesola, Iranloye, et al., 2019). Accessible and reliable indicators for developmental delays are a drop in fetal body weight and length. The reduced ossification of the fetal skeleton may be a probable reason for the decrease in fetal weight. Adverse effects of chemicals administered during gestation, such as a decrease in fetal weight, can be demonstrated by retarding fetal development (Abd El-Aziz, El-Fark, et al., 2012). The fetal skeleton is an important predictor of embryo health growth in developmental research and changes in the bone structure usually represent shifts in the mother-fetal environment Inadequate ossification of many bones can be associated with the influence of herbicides on calcium metabolism and/or bone morphometry by reducing the availability of calcium and magnesium ions to the growing fetus, thereby causing retardation in bone growth (Seif 2014). In addition, delayed ossification may be attributed to a variety of generalized factors that could influence maternal health, such as changes in female body weight, food intake, or general physiology (Carney and Kimmel 2007).

The retardation of fetus growing and higher incidence of external and skeletal abnormality rate can be due to oxidative stress induced by applying pesticides. This viewpoint is reinforced by the current biochemical study and excessive reactive oxygen species (ROS) creation by increasing the amount of MDA and reducing catalase activity. Oxidative stress disrupts embryos by inducing membrane phospholipid peroxidation and by modifying the plurality of cellular structures, such as lipids, proteins, and nucleic 
acids. The implications of this damage involve mitochondrial disturbances, blockage of the embryo cells, and loss of adenosine triphosphates (Mazhar, Moawad, et al. 2014). Measurements of oxidative stress markers in maternal blood show that pregnancy is a state of oxidative stress due to the high metabolic activity of the placenta and maternal metabolism in pregnancy (Myatt, 2010). Oxidative stress is now recognized as a central agent associated with complications linked to pregnancy and may be a factor in the pathophysiology of various fetal and neonatal disorders Maternal circulation during pregnancy is linked with a threefold increase in the amount of oxygen in the placenta and also this transition period is combined with an upsurge in ROS contributing to the maternal circulation of the oxidative stress Additional oxygen delivery to the fetus occurs during placental maturation to sustain the elevated metabolism during the fast growth process of the fetus (Ahmed and Rahman, 2015 ).

Pathologically elevated ROS may mediate skeletal delay in fetal development and altered organogenesis in the embryos. The phases of embryonic and fetal development are thought to be particularly prone to high rates of ROS in part because of the effective free radical scavenging systems (Ornoy, 2007).

Supplementation of pregnant rats with NSO ameliorated the effect of the herbicide on maternal- fetotoxicity. Along with its derivatives, $\mathrm{N}$ sativa has been used as a therapy for liver diseases, rheumatism, and other inflammatory disorders (Al-Khalaf and Ramadan, 2013). Nigella sativa oil has more unsaturated fatty acids, such as linoleic acids and oleic acids. Whereas oleic acid raised levels of $\mathrm{Ca}^{+2}$ and preserved bone density and reduced calcium loss by supporting mineral absorption in the body (Seif, 2014). Nigella sativa oil cytoprotective effects and its main active ingredient, thymoquinone, are predominantly regulated by anti-inflammatory and antioxidant activities. The antiinflammatory activity can be due to the inhibition of several pro-inflammatory mediators mRNA expressions (Vaillancourt, Silva, et al., 2011). A number of clinical studies have identified the anti-inflammatory and antioxidant properties of NS. Because of inhibition, both NS crude oil and pure thymoquinone decreased eicosanoid generation in peritoneal leukocytes of rats. Both substances, particularly thymoquinone, also inhibited nonenzymatic peroxidation in the liposomes of brain phospholipids. Alternatively, the administration of thymoquinone reduced inflammatory processes and ROS activation (Arif, Thakur, et al., 2016). Significant improvement in the treatment of diabetic rats with N. sativa on biochemical and oxidative biomarkers as well as in pancreatic and nephrotic histopathological injury was demonstrated by (El Rabey, Al-Seeni et al., 2017). In addition to this, the crude $\mathrm{N}$ fixed oil. Sativa and thymoquinone (TQ) have also been found to inhibit lipid peroxidation in the membrane and to improve cellular antioxidant systems (Mosbah, Yousef, et al., 2016).

Focal necrosis and fatty change in liver tissues may be attributed to that some toxic metabolites may be transported to the liver, resulting in cell death (Benjamin, et al., 2006). These features of hepatic pathology have been attributed to mitochondrial dysfunction and hepatic tissue hypoxia (Khan and Hansen 2003). Marked congestion and hemorrhage were observed in hepatic tissue as an inflammation sign of induced by a toxic agent such as the applied herbicide. Inflammatory compounds (histamine and cytokines) liberated from damaged cells, causing increased blood flow into the capillary bed which induced vasodilation (Nagao, Fukuizumi, et al., 2003). Hepatotoxic materials cause damage to hepatocytes those results in hepatic fibrosis characterized by the deposition of collagen, proteoglycans, and glycoproteins caused by dysregulation of physiological wound healing (Kisseleva and Brenner 2006). Whereas, xenobiotic metabolites induce hepatocyte damage through inflammation-related cytokines and fibrogenic mediators induced by the release of reactive oxygen species. 


\section{REFERENCES}

Abd El-Aziz, G. S., M. M. El-Fark and H. A. Saleh (2012). "The prenatal toxic effect of methylmercury on the development of the appendicular skeleton of rat fetuses and the protective role of vitamin E. Anatomical Record (Hoboken), 295(6): 939-949.

Aebi, H. (1984). Catalase in vitro. New York, Academic press.

Ahmed, T. H. and M.M. Rahman M.M. (2015): An Overview of Oxidative Stress and Its Effect on Fetal Development and Organogenesis. American Journal of Biopharmacology Biochemistry and Life Sciences, Volume 04: Issue 02 Page 27-53

Al-Gubory, K. H., P. A. Fowler and C. Garrel (2010). "The roles of cellular reactive oxygen species, oxidative stress and antioxidants in pregnancy outcomes. The International Journal of Biochemistry \& Cell Biology, 42(10): 1634-1650.

Alcolea, M. P., B. Colom, I. Llado, F. J. Garcia-Palmer and M. Gianotti (2007). "Mitochondrial differentiation and oxidative phosphorylation system capacity in rat embryo during placentation period. Reproduction, 134(1): 147-154.

Alenzi F.Q., M.A. A. Altamimi, O. Kujan, B. Tarakji, W. Tamimi (2013): Antioxidant properties of Nigella sativa. Journal of Molecular and Genetic Medicine, 7:77

Al-Khalaf, M. I. and K. S. Ramadan (2013): Antimicrobial and Anti-cancer Activity of Nigella sativa oil-A Review. Australian Journal of Basic Applied Science, 7: 505514

Al-Sa'aidi J. A. A., A. L. D. Al-Khuzai and N. F. H. Al-Zobaydi (2009): Effect of alcoholic extract of Nigella sativa on fertility in male rats. Iraqi Journal of Veterinary Sciences, Vol. 23, Supplement II, (123-128)

Al-shdefat R. I., M. A.Abd-Elaziz, F. I.Al-Saikhan (2014) Genoprotective and genotoxic effects of thymoquinone on doxorubicin-induced damage in isolated human leukocytes. Tropical Journal of Pharmaceutical Research, 13(12):2015-2020

Apostoli, P. and S. Catalani (2015): Effects of metallic elements on reproduction and development, in: F.G. Nordberg, A.B. Fowler, M. Nordberg (Eds.). Handbook on the Toxicology of Metals, Academic Press Elsevier, USA, pp. 399-419.

Arif, M., S. C. Thakur and K. Datta (2016). "Implication of thymoquinone as a remedy for polycystic ovary in rat. Journal of pharmaceutical biology, 54(4)674-685.

Banchroft, J.D., A., Stevens, and D.R. Turner, (1996): Theory and practice of histological techniques. Fourth Ed. Churchil Livingstone, New York, London, San Francisco, Tokyo.

Benjamin N, A. Kushwah, R. K Sharma., A. K Katiyar(2006).Histopathological changes in liver, kidney and muscles of pesticides exposed malnourished and diabetic rats. Indian Journal of Experimental Bibliology. 44(3):228-232.

Beutler, E., O. Duron and B. M. Kelly (1963). "Improved method for the determination of blood glutathione. Journal of laboratory and clinical medicine, 61: 882-888.

Carney, E. W. and C. A. Kimmel (2007). "Interpretation of skeletal variations for human risk assessment: delayed ossification and wavy ribs. Birth Defects Reseach B Developmental and Reproduction Toxicolology, 80(6): 473-496.

Caserta, D., A. Graziano, G. Lo Monte, G. Bordi and M. Moscarini (2013). "Heavy metals and placental fetal-maternal barrier: a mini-review on the major concerns. European Review for Medical and Pharmacological Sciences, 17(16): 2198-2206.

Desforges, M. and C. P. Sibley (2010). "Placental nutrient supply and fetal growth.The International Journal of Developmental Biology, 54(2-3): 377-390.

El Ghareeb, A.E.W., H. Hamdi, E.S.F. Taha and H. Ali, (2015): Evaluation of teratogenic potentials of bronchodilator drug on offsprings of albino rats. International 
Journal. Of Scientific and Engineering. Research, 6: 534-542.

El Rabey, H. A., M. N. Al-Seeni and A. S. Bakhashwain (2017). "The Antidiabetic Activity of Nigella sativa and Propolis on Streptozotocin-Induced Diabetes and Diabetic Nephropathy in Male Rats." Evid Based Complement Alternat Med 2017: 5439645. model of amyloid-beta-induced Alzheimer's disease. Advanced Biomedical Research, 4: 131.

Gabr, G.A., A.G. Soliman, S.S. Abdulaziz, A.A. Al-Kahtani and B. E. Ali (2015): Teratogenic Effects in Rat Fetuses Subjected to the Concurrent in utero Exposure to Emamectin Benzoate Insecticide. Pakistan Journal of Biological Sciences, 18 (7): 333-340

Gundacker, C., J. Neesen, E. Straka, I. Ellinger, H. Dolznig and M. Hengstschlager (2016). "Genetics of the human placenta: implications for toxicokinetics. Archives of Toxicology, 90(11): 2563-2581.

Gupta, S., P. Sarotra, R. Aggarwal, N. Dutta and N. Agnihotri (2007). "Role of oxidative stress in celecoxib-induced renal damage in wistar rats.Digestive Disease and Science, 52(11): 3092-3098.

Habig, W.H., M.J., Pabst and W.B., Jacoby (1973): Glutathione-S-transferees: the first step in mercapturic fermentation. Journal of. Biochemistry, 249: 7130-7139.

Hayes, A.W. (1986): Principles and Methods of Toxicology. Raven Press, USA.

Islam M.H., I.Z. Ahmad, M.T. Salman (2015). Neuroprotective effects of Nigella sativa extracts during germination on central nervous system. Pharmacognosy Magazine, 11(Suppl 1):S182-S189. doi:10.4103/0973-1296.157729

Kanter, M. (2011). "Thymoquinone reestablishes spermatogenesis after testicular injury caused by chronic toluene exposure in rats.Toxicology and Industerial Health, 27(2): 155-166.

Khan, M. A. and L. G. Hansen (2003). "Ortho-substituted polychlorinated biphenyl (PCB) congeners (95 or 101) decrease pituitary response to thyrotropin releasing hormone.Toxicology Letter, 144(2): 173-182.

Kisseleva, T. and D. A. Brenner (2006). "Hepatic stellate cells and the reversal of fibrosis.Journal Gastroenterology \& Hepatology, 21 Suppl 3: S84-87.

Majdalawieh, A. F. and M. W. Fayyad (2015). "Immunomodulatory and antiinflammatory action of Nigella sativa and thymoquinone: A comprehensive review. International Immunopharmacology, 28(1): 295-304.

Mansour, S. W., S. Sangi, S. Harsha, M. A. Khaleel and A. R. Ibrahim (2013). "Sensibility of male rats fertility against olive oil, Nigella sativa oil and pomegranate extract. Asian Pacific Journal of Tropical Biomedicine, 3(7): 563568.

Mazhar, F. M., K. M. Moawad, M. H. El-Dakdoky and A. S. Amer (2014). "Fetotoxicity of 2,4-dichlorophenoxyacetic acid in rats and the protective role of vitamin E. Toxicology and Industerial Health, 30(5): 480-488.

Milesi MM, Alarcón R, Ramos JG, Muñoz-de-Toro M, Luque EH, Varayoud J. Neonatal exposure to low doses of endosulfan induces implantation failure and disrupts uterine functional differentiation at the pre-implantation period in rats. Molecular and Cellular Endocrinology, 2015;401:248-259. doi: 10.1016/j.mce.2014.11.028

Mosbah, R., M. I. Yousef, F. Maranghi and A. Mantovani (2016). "Protective role of Nigella sativa oil against reproductive toxicity, hormonal alterations, and oxidative damage induced by chlorpyrifos in male rats.Toxicology and Industerial Health, 32(7): 1266-1277.

Mohamadin A.M., B. Sheikh, A. A. Abd El-Aal, A.A. El-Berry and F.A.Al-Abbasi (2010) Protective effects of Nigella sativa oil on propoxur induced toxicity and 
oxidative stress in rat brain regions. Pesticide Biochemistry and Physiology, 98: $128-134$.

Myatt, L. (2006). "Placental adaptive responses and fetal programming. Journal of Physiology, 572(Pt 1): 25-30.

Myatt, L. (2010). "Review: Reactive oxygen and nitrogen species and functional adaptation of the placenta. Placenta, 31 Suppl: S66-69.

Nagao, Y., K. Fukuizumi, R. Kumashiro, K. Tanaka and M. Sata (2003). "The prognosis for life in an HCV hyperendemic area. Gastroenterology, 125(2): 628-629.

Ohkawa, H., N. Ohishi and K. Yagi (1979). "Assay for lipid peroxides in animal tissues by thiobarbituric acid reaction.Analatical Biochemistery, 95(2): 351-358.

Ornoy, A. (2007). "Embryonic oxidative stress as a mechanism of teratogenesis with special emphasis on diabetic embryopathy.Reproduction Toxicology, 24(1): 3141.

Oyesola, T., B. Iranloye and O. Adegoke (2019). "Implantation and pregnancy outcome of Sprague-Dawley rats exposed to pirimiphos-methyl.Endocrine Regulations, 53(3): 139-145.

Peiris-John, R. J. and R. Wickremasinghe (2008). "Impact of low-level exposure to organophosphates on human reproduction and survival.Transactions of the Royal Society of Tropical Medicine and Hygiene, 102(3): 239-245.

Seif, A. A. (2014). "Nigella Sativa reverses osteoporosis in ovariectomized rats.BMC Complementary and Alternative Medicine, 14: 22.

Stillerman, K. P., D. R. Mattison, L. C. Giudice and T. J. Woodruff (2008). "Environmental exposures and adverse pregnancy outcomes: a review of the science.Reproductive sciences, 15(7): 631-650.

Toni, C., C. C. de Menezes, V. L. Loro, B. E. Clasen, R. Cattaneo, A. Santi, A. Pretto, R. Zanella and J. Leitemperger (2010). "Oxidative stress biomarkers in Cyprinus carpio exposed to commercial herbicide bispyribac-sodium.Journal of Applied Toxicology, 30(6): 590-595.

Vaillancourt, F., P. Silva, Q. Shi, H. Fahmi, J. C. Fernandes and M. Benderdour (2011). "Elucidation of molecular mechanisms underlying the protective effects of thymoquinone against rheumatoid arthritis.Journal of Cell Biochemistery, 112(1): 107-117.

Valko, M., D. Leibfritz, J. Moncol, M. T. Cronin, M. Mazur and J. Telser (2007). "Free radicals and antioxidants in normal physiological functions and human disease. International Journal of Biochemistery Cell Biology, 39(1): 44-84.

Varayoud, J., J. G. Ramos, M. Munoz-de-Toro and E. H. Luque (2014). "Long-lasting effects of neonatal bisphenol A exposure on the implantation process.Vitamines and Hormones, 94: 253-275. 